\title{
PENETRATION OF CHARGED PARTICLES IN MATTER
}

D URING September 15-18, 1958, an informal conference was held at Gatlinburg, Tennessee, to discuss the penetration of charged particles in matter. Penctration of Charged Particles in Matter : Proceedings of an Informal Conference, Gatlinburg, Tennessee, September 15-18, 1958. Edited by A. Vehling. (Nuclear Science Series, Report No. 29. Publication No. 752.) Pp. $x+174$. (Washington, D.C. : National Academy of Sciences-National Research Council, 1960.) 2 (dollars.) The conference, which was attended by about fifty scientists from Canada, Europe, Asia and the United States of America, was organized by the Sub-cominittee on Penetration of Charged Particles in Matter of the National Academy of Sciences-National Research Council and sponsored by the United States Atomic Energy Commission, National Science Foundation, and the Air Force Office of Scientific Research.

About twenty-five talks were given and the pro(eedings of the conference, edited by E. A. Vehling of the University of Washington, have now been published. Topies ranging from the reliability of experimental data to new approaches in the theoreti(:al description of energy-loss mechanisms were discussed. The papers are presented under five head- ings : stopping power and range, recent developments in the theory of stopping power, charge-changing collisions, atomic and molecular scattering, ionization in gases by high-energy particles, and microscopic: and macroscopic energy-loss distributions.

Prof. S. K. Allison, who introduced the papers on charge-changing collisions, discusses measurements on the formation of negative lithium ions, and $\mathrm{C}$. $\mathrm{Y}$. Fan explains briefly the spectroscopic study of electron-capture processes. U. Fano summarizes the various theoretical reviews given in the final section of the proceedings dealing with energy-loss distributions and adds an appendix in which he comments on 'collective' effects in atoms and in extended media. J. B. Hasted, of University College, London, the only representative from the United Kingdom, reports on coincidence methods of studying inelastic ionic: (:ollisions.

The articles have been prepared ejther by the speakers or by the chairmen of the various sessions in collaboration with the speakers. In some instances the reports include the results of the subsequent, discussions. In a few cases the original reports have been shortened or reduced to abstract form because of publication of the full roport elsewhere. References are given.

\section{EQUATORIAL SPREAD-F AND F-LAYER HEIGHTS}

\author{
By DR. A. J. LYON and DR. N. J. SKINNER \\ University College, Ibadan, Nigeria \\ AND \\ Prof. R. W. WRIGHT
}

University College of Ghana, Legon, Ghana

\begin{abstract}
W ${ }^{\mathrm{E}}$ recently reported ${ }^{1}$ on the surprising inverse correlation observed near the magnetic oquator between the occurrence of spread- $F$ echoes and magnetic disturbance, in contrast to the direct correlation observed at temperate latitudes. The evidence then presented related to the exceptionally disturbed month of September 1957 and was derived from observa tions at only a few ionospheric stations. We have now extended our analysis to cover a twelve-month period of the International Geophysical Year (November 1957-October 1958), and have used observations from about sixty stations distributed over a wide range of magnetic latitude. In addition we have made a parallel study of the rapid rise in the height of the equatorial $F$-layer which occurs just after local sunset (from about $300 \mathrm{~km}$. to more than $400 \mathrm{~km}$. in 1-2 hr.). It
\end{abstract}

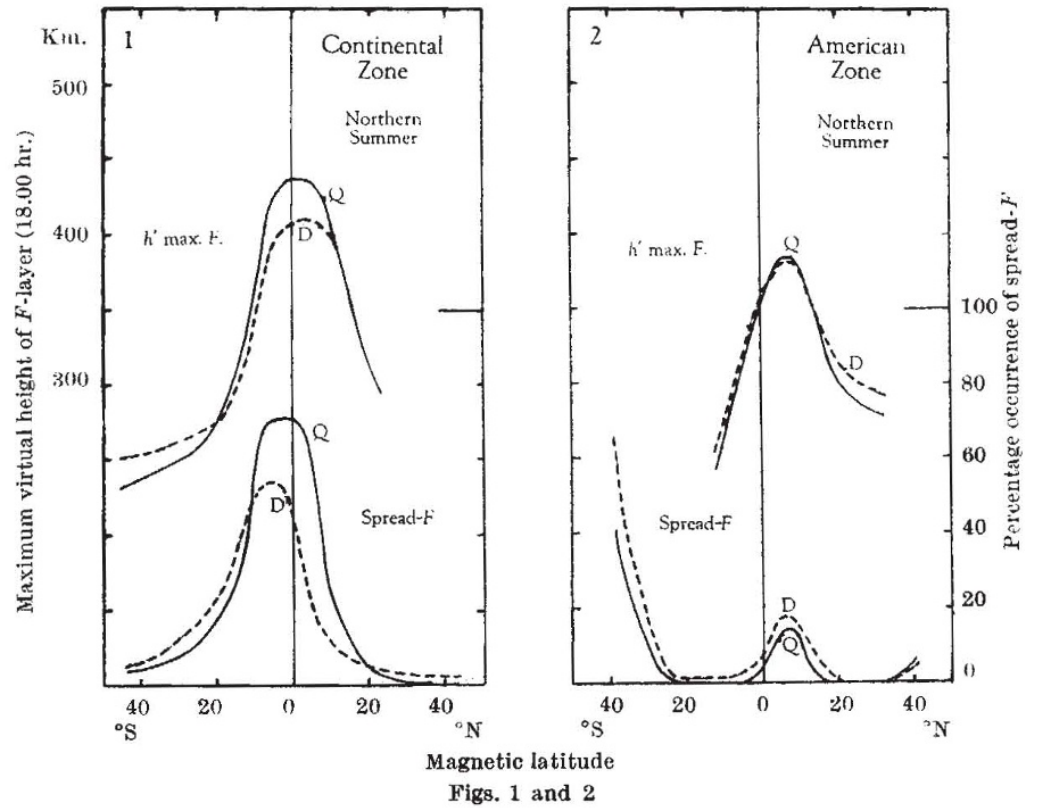

